Too much love will kill you: the development and function of group emotional awareness

\begin{tabular}{|r|l|}
\hline Journal: & Team Performance Management \\
\hline Manuscript ID & TPM-07-2019-0081.R1 \\
\hline Manuscript Type: & Research Paper \\
\hline Keywords: & $\begin{array}{l}\text { group emotional awareness, group emotion regulation, emergent state, } \\
\text { task conflict, relationship conflict }\end{array}$ \\
\hline \multicolumn{2}{|l}{} \\
\hline
\end{tabular}

SCHOLARONE ${ }^{m}$

Manuscripts 
Running head: The development and function of group emotional awareness

\title{
Too much love will kill you: the development and function of group emotional awareness
}

\begin{abstract}
Purpose

We aim to enhance clarity for the conceptualization and measurement of group emotional awareness by defining it as an emergent state. We explore the emergence of this state through two studies designed to explore the four characteristics (global, radically novel, coherent and ostensive) of emergent phenomena (Waller et al., 2016).

Design/methodology/approach

In Study 1 we explore in an experimental setting the formation of group emotional awareness and regulation as emergent states as a result of compositional effects (team members' self-perceptions of their individual emotional awareness capabilities) and group norms regarding emotional awareness. Study 2 uses an experimental design to explore how pre-existing expectations of group emotional awareness, based on previous dyadic interactions between team members, can prevent conflict escalation (from task to relationship conflict) in project teams.
\end{abstract}

\section{Findings}

(1) Individual perceptions of members' own abilities and group norms interact in the emergence of group emotional awareness and (2) group emotion regulation can develop only under an optimal level of emergent group emotional awareness: Groups that build emotional awareness norms compensate for their members' low awareness and develop equally efficient regulatory strategies as groups formed of emotionally aware individuals. However, the conjunction of personal propensity towards awareness and explicit awareness norms blocks the development of regulatory strategies. (3) Group emotional awareness (both as a developed state and as an expectation) reduces the escalation of task to relationship conflict.

Originality/value

Designing for the exploration of the four characteristics of emergence allowed us to gain new insights about how group emotional awareness emerges and operates: too much awareness can hurt, and affective group expectations have the power to shape reality. These findings have strong implications for practitioners' training of emotional awareness in organisations.

\section{Keywords}

group emotional awareness; group emotion regulation; emergent state; task conflict; relationship conflict; expectations. 
Running head: The development and function of group emotional awareness

\section{Introduction}

Group emotional awareness (GEA) has largely been the ugly duckling in the research story of group emotional capabilities (i.e., group emotional awareness and regulation). Previous research has primarily focused on the role that group emotion regulation (i.e., the capacity of a team to work with emotions felt/expressed as a result of group interactions - Yang \& Mossholder, 2004) plays in group processes, especially in decoupling the co-occurrence of task and relationship conflicts (Ayoko, Callan \& Härtel, 2008; Yang \& Mossholder 2004; Curșeu, Boroș \& Oerlemans, 2012). Less evidence exists, however, on the impact of group emotional awareness (i.e., a team's capacity to identify the emotions felt/expressed as a result of group ${ }^{1}$ interactions - Yang \& Mossholder, 2004). Moreover, the existing studies reveal contradictory findings about its role in group processes: while some (Boroș, Van Gorp et al, 2016; Boroș, under review) argue that it has a positive impact in decoupling task from relationship conflict, leading to improved team coordination and effectiveness, others (Elfenbein, Foo et al, 2007) offer evidence of instances when heightened group emotional awareness is detrimental for group effectiveness. A comprehensive analysis of how group emotional awareness emerges and operates, which could explain these contradictory findings, is so far missing. To address this gap and contribute to conceptual clarification efforts of GEA, the current paper sets out to answer the following questions: what is group emotional awareness: how does it come to be: and how does it relate to other emotional capabilities (i.e., group emotion regulation) and other group processes (e.g., conflict).

We propose to address these questions by using emergent states as a lens to define GEA. Emergent states are "constructs that characterize properties of the team that are typically dynamic in nature and vary as a function of team context, inputs, processes, and outcomes" (Marks, Mathieu, \& Zaccaro, 2001: 357). They "arise from micro levels, are both irreducible and autonomous from the underlying level, endure for some period of time, and can exert downward causal forces or "mutual causality" that affect the underlying parts" (Waller, Okhuysen \& Saghafian, 2016: 565). Emergent states share four characteristics: they are (1) global (emergent properties are conceptualized to emerge from lower- or micro-level components and interaction), (2) coherent (over time, emergent states endure and might vary), (3) ostensive (are experienced by group members) and (4) radically novel (holistic emergent states can neither be reduced back to component parts not perfectly predicted from them) (Waller et al., 2016). In the pursuit of conceptual clarity and gaining new insights about how GEA emerges and operates, we design our studies to explore these four characteristics. In doing so, we respond to the existing limitation in the group dynamics field, which is to privilege "static aggregation of constructs to approximate emergent phenomena rather than investigate and chart the dynamic interaction that gives

\footnotetext{
${ }^{1}$ Throughout this paper, we will use the terms 'group' and 'team' interchangeably, meaning the same type of unit: a collection of individuals sharing a common goal who interact and are interdependent in their efforts to reach that goal.
} 


\section{Running head: The development and function of group emotional awareness}

rise to novel states, patterns and structures. [...] the methodologies used to explore emergent states fail to capture the global essence of these phenomena" (Waller et al., 2016:572).

First, we explore the extent to which group emotional awareness is truly global and radically novel. The first aim of our study is to explore how the compositional effects and group norms interact to give rise to group emotional awareness, and what are the conditions in the development of group emotional awareness that then support or prevent the subsequent emergence of group emotion regulation. To reach this aim, we conceptualize and measure group emotional awareness as an emergent state (Jordan \& Troth, 2004) resulting through group interactions (Ayoko et al, 2008), at the intersection of compositional effects (bottom-up approach - i.e., the affective composition of the group given by the average/minimum/maximum or diversity of individual members' emotional awareness - Elfenbein, 2006) and group norms (top-down approach). We test whether GEA can be defined as global by exploring if its emergence depends on micro-level components - such as individual emotional awareness - and group interactions with their emotional awareness norms. We also test whether it is radically novel (i.e., cannot be reduced to its parts, nor can it or its impact be fully predicted by them) by studying the emergence of GEA in relation to the subsequent emergence of group emotional regulation.

Through our first aim, we also explore a third characteristic of emergence: coherence. Coherence refers to the endurance of emergent states as a whole over time, along with their capacity to change and their potential to influence interactions that occur subsequent to emergence (Waller et al., 2016). So far, a "notable absence in the study of emergent states" is "the duration in time it may take for an emergent state to appear or to change.[...] in this literature, we treat all emergent states as having similar temporal properties and trajectories" (Waller et al., 2016: 587). By focusing on the interactional conditions that lead to the emergence of GEA, and by showing how the emergence of GEA is a temporal precondition to the emergence of group emotion regulation, we expand the exploration of coherence and align with recent research that looks into the (temporal) dynamics of various emotional capabilities (i.e., the cascading model of Joseph and Newman, 2010).

Finally, we take the exploration of temporal dynamics (i.e., coherence) one step further and link it to ostensiveness (i.e., emergent states are experienced by their members). We suggest that the experience of an emergent state (in this case GEA) reflects not only the present and the past, but the future as well. Groups do not just reflect on their capabilities and emotional history (Barsade \& Gibson, 2012); they are also driven by expectations - hence, the future dimension. And just as previous research demonstrated that self-efficacy beliefs impact future performance and group behaviours (Tasa, Tagar \& Seijts, 2007), we assume that expectations around group emotional awareness will have the same function as group emotional awareness itself. We explore this proposition through an experimental study (Study 2) in which we look at the impact that expected group emotional awareness has on decoupling task and relationship conflict. Previous research (Boroş, under review) has already 
Running head: The development and function of group emotional awareness

demonstrated that group emotional awareness as an emergent state decouples task and relational conflict. We now want to see if expectations regarding GEA are already enough to create an impact.

Thus, our second aim is to show through experimental evidence that group emotional awareness as an emergent state (both as a given or as an expectation) impacts subsequent group processes (such as the evolution of conflict) and emergent states (e.g., group emotion regulation).

To summarize, we set out to explore (1) the development of group emotional awareness at the intersection of bottom-up and top-down processes (global and radically novel), and (2) how group emotional awareness, as an emergent state, further influences group processes (specifically conflict) and the development of other group abilities (i.e., group emotion regulation) (ostensive and coherent).

\section{Theoretical background}

Group emotional awareness: bottom-up and top-down approaches

With the aim of creating conceptual clarity, we begin the build-up of our model by reviewing previous research on group emotional awareness in both bottom-up and top-down approaches. We included in our review studies that used different terminology but referred content-wise to the same aspect covered in our definition of group emotional awareness. In doing so, we try to argue why including both the topdown and bottom-up approach of GEA will shed new light on how group emotional awareness as an emergent state is shaped, and how that in turn influences the development of group emotion regulation.

Bottom-up approach: compositional aspects. Emotional awareness refers to the ability to detect, decipher and identify emotions in oneself and the others, as well as understand their cause, how they evolve and the relationships between them (Salovey \& Mayer, 1990). The majority of extant research has measured group emotional awareness at the individual level (in other words, the group members' individual emotional awareness) and aggregated these individual indicators at the group level by computing the group average (Black, Kim et al, 2019; Jordan \& Troth, 2004) or in addition, looking at minimum and maximum individual scores in a team (Quoidbach \& Hansenne, 2009).

Top-down approach: group norms. The top-down conceptualization of group emotional awareness (and regulation) is based on the work of Druskat and Wolff (2001). They define group emotional intelligence as the group's ability to create norms that encourage expression, awareness and regulation of the emotional process that lead to improving the ability of group members to work together effectively (Druskat \& Wolff, 2001). Seen as a dimension of group emotional intelligence, group emotional awareness consists of group norms that encourage the awareness of individual and group level emotions and moods arising in group interactions. According to these authors, groups develop two types of norms that support group emotional awareness: interpersonal understanding and perspective taking. Selfmanaged work groups that develop these two types of norms are then capable of 'heedful interrelating'. 
Running head: The development and function of group emotional awareness

According to Druskat and Pescosolido, "interpersonal interactions assembled with heed are attentive, purposeful, conscientious and considerate. They increase team effectiveness by improving members' ability to work together efficiently [...]. Without the enactment of heed, interpersonal interactions and relationships are paid little regard" (Druskat \& Pescosolido, 2002: 293). Consequently, teams that develop these norms are more adaptive, flexible and perform better. Previous experimental research also showed that when diverse teams lacking diversity beliefs are given group emotional awareness norms, these norms counteract the negative impact on team performance due to lack of diversity beliefs (Boroș \& Curșeu, 2013). In other words, interventions promoting group emotional awareness norms can help to compensate for missing capabilities of the group.

Group emotional awareness as an emergent state. Starting from Marks et al.'s 2001 framework, we look at group emotional awareness as an emergent state by considering the interaction of compositional effects (individual EI of team members) and group norms aimed at increasing group emotional awareness. Previous empirical data indicate the need to consider this interaction. For example, Jordan $\&$ Troth (2002) report in their research that work teams with lower average emotional awareness (estimated as the aggregated measure of the members' individual emotional intelligence), initially performed at a lower level than high emotionally aware teams. Over the 10 weeks of the study however, teams low on emotional awareness eventually achieved the same level of performance as teams high on emotional awareness. Jordan and Troth speculated that the training teams had received during this period might have contributed to this performance improvement. We suggest that an alternative framing for these findings is these teams have developed over time norms that support the awareness (and probably also regulation) of the emotional processes that occur in the group and thus improved their group emotional awareness. In other words, they have moved beyond their members' individual capacities and developed a group emotional intelligence.

We concur with the view that group emotional awareness is an emergent state that depends both on members' individual emotional awareness as well as on the norms for creating an empathic environment in which attention is paid to members' individual emotions, as well as the group moods. The question that arises here is what is the optimal level of awareness in a team? Is the more (individual plus norms) the better for team functioning or can you actually have too much of a good thing? Resource allocation theory supports the idea that we have a finite resource pool (Ackerman \& Kanfer, 2009) from which emotion awareness and regulation draw. Groups with emotionally aware individuals (with emotional awareness measured as an ability - i.e., the ability paradigm), and even more so individuals who describe themselves as very emotionally aware (measured through self-reports - i.e., the mixed emotional intelligence paradigm), will automatically allocate resources for the identification and appraisal of emotions generated by group interactions. Should there also be norms specifying this needs to be done, groups may end up allocating too many resources to perceiving and understanding the affective dynamics as they unfold. This makes subsequent regulation, basic decision making (Vohs, 
Running head: The development and function of group emotional awareness

Baumeister et al., 2008) and persistence in the task (Baumeister, Bratslavsky et al., 1998) more difficult. In other words, an excess of group emotional awareness overloads the group and blocks subsequent adaptive reactions, such as regulating the emotions and allocating resources to resolve the task at hand. This perspective is supported by evidence from previous research reporting that emotional awareness in and of itself can sometimes block adaptive responses of a team. While Elfenbein et al. (2007) report in a one-year study of teams in public service that the ability of team members to understand each other's emotional expressions explained $40 \%$ of the variance in team performance over the course of a year, it was only the accuracy in understanding positive emotions which predicted better team performance. In contrast, accuracy in understanding negative emotions predicted an impaired team performance, team members liking each other less and a decreased desire to work together again (spirals of negative energy). In this sample, participants were young adults on their first job, who appeared to lack the skills to use negative emotions productively (instead of seeing them as signs, they reacted defensively and escalated conflict). Elfenbein and co-authors (2007) do not argue against heightened abilities of perceiving negative emotions, but advise considering contingent factors that affect their impact for teamwork. For instance, they argue that some tasks and situations call more for understanding negative emotions to prevent negative spirals. Also, they caution that "in the absence of effective emotion regulation skills, it may be better not to have strong emotional perception skills" (Elfenbein et al. 2007: 180). In other words, if automatic regulation behaviours cannot occur and need attention from the group to be built, it may be that the group lacks the capacity to allot the appropriate amount of resources to do so.

Similarly, in a study investigating the relationships between emotional intelligence, performance, and cohesiveness in 23 nursing teams, Quoidbach and Hansenne (2009) report that while health care quality and group cohesiveness were positively correlated with emotion regulation, emotion awareness correlated negatively with the health care provided by the team but positively with cohesion. These results indicate the possibility that teams high in emotion appraisal might sometimes be too preoccupied with relational aspects of teamwork more than the task itself. In other words, teams selectively choose which aspect of the teamwork to allot most resources to, and emotional awareness might bias this selection in favour of relational aspects.

This effect should be more apparent when individual emotional awareness is measured via self-reports (i.e., mixed-EI methods) rather than ability tests (Joseph et al. 2015). In their recent meta-analysis, Joseph and her colleagues notice a superior predictive value of self-reports EI measures for workplace outcomes. They argue that EI self-perceptions will always have a higher impact on behaviour because this is meta-level knowledge (cognitions about my abilities rather than actual abilities). In fact, Salovey and colleagues (1995) defined the 'mixed-EI methods approach' as 'meta-moods'. Meta-mood has been defined as a reflective process that accompanies mood states, more specifically, an "ongoing process associated with moods whereby individuals continually reflect upon their feelings, monitoring, 
Running head: The development and function of group emotional awareness

evaluating, and regulating them" (Salovey, Mayer et al., 1995: 127). Analogously, meta-cognitions have been long proven to be more predictive of performance than cognitions in themselves: knowing what you know allows you to calibrate behaviour and make better use of existing resources (Wegner, 1987; King, 2017; Michinov \& Juhel, 2019) than simply knowing something. Similarly, individuals who know what they feel and how well they can cope with emotions will be better able to use these skills and regulate their emotional experience. Following the same argument, when given norms that enhance group emotional awareness, team members who think themselves to be endowed with high emotional awareness, will (in a bid for internal consistency) allot too much time and effort to pay attention to group dynamics, to the detriment of developing strategies to deal effectively with them and focus on the task. Therefore, we predict that:

Hypothesis 1: Group emotional awareness norms moderate the impact of group members' emotional awareness on group emotion regulation in such a way that: in groups where members have a higher perceived emotional awareness, the presence of awareness norms is detrimental for the development of group emotion regulation, whereas in groups where members have a lower perceived emotional awareness, the presence of awareness norms is beneficial for the emergence of group emotion regulation.

With Hypothesis 1 we explore emergence at the intersection of individual traits (perceived individual emotional awareness) and group norms, thereby focusing on the global quality (i.e., the emergent state is given by the dynamic interaction of the two components and is irreducible to either component). Furthermore, in exploring the impact of group emotional awareness on regulation, we also demonstrate that GEA is radically novel, in that neither its emergence nor its subsequent impact on other emergent states can be fully predicted by its lower-level constituent parts (Waller et al., 2016). Next, we focus on the emergent state's characteristics of coherence and ostensiveness.

Coherence brings the time dimension into the depiction of emergence: emergent phenomena require a certain amount of temporal sustainability (so they are not fleeting), they vary over time (so they are not static), and they have the potential to influence dynamics that occur subsequent to their emergence. This potential "provides the avenue for at least two resulting effects: team members' experiences of an emergent state, and the influence of an emergent state directly on team members' behavioursincluding their deliberate attempts to change the state" (Waller et al., 2016: 578). In this way, coherence is directly linked to ostensiveness. The ostensive character of an emergent state refers to the fact that team members recognize and react (consciously or unconsciously) to their experience of that state, and in so doing the emergent state impacts their subsequent behaviour. This characteristic generated research that looks into emergence in a new way: rather than the emergent state having to be named, 
Running head: The development and function of group emotional awareness

recognized or discussed explicitly, it assumes that emergence has occurred if there is impact on group dynamics and team members' behaviours. These reactions in turn shape the emergent state further, making it dynamic (as coherence predicates).

These considerations are relevant for the study of emergence in that they raise questions about the minimal conditions needed for emergent states to occur. Santos and Passos (2013) showed that preexistent similarities in team members' mental models about conflicts has an impact on the actual levels of conflicts experienced in teams, as this similarity makes them more likely to avoid disagreements regarding personal and social issues. Similarly, Tasa, Taggar, and Seijts (2007) show that initial levels of collective efficacy influence members' subsequent individual-level teamwork behaviour due to the fact that members are more likely to engage in activities that contribute to the team's task and goal accomplishment when they feel they are working in efficacious groups (a hypothesis long-supported in research on self-efficacy beliefs). But what are the implications that these findings from other emergent states open for group emotional awareness?

In Study 1 we looked at the interplay of individual members' self-reported emotional awareness and group norms, that is, elements that intervene at an early stage to shape the emergence of GEA. This allows us to see GEA as emerging early on in a workgroup's life and having potential for substantial influence in the group dynamics and performance down the line. Previous research showed that early GEA can decouple task from relationship conflict (Boroș, under review) and can even mitigate the impact of conflict asymmetry on group performance in highly conflictual situations (Boroș et al., 2016).

But research on the ostensiveness of emergent phenomena suggests we can move the timeline of emergence even earlier. We already know that prior history (both individual and shared) shapes the expectations of team members about their subsequent affective interactions (Kelly \& Barsade, 2001): previous research suggests that even a one-off emotional event in a group's history is enough to give rise to such collective meta-moods and thus create expectations of how future affective interactions will proceed (Kelly \& Barsade, 2001). Furthermore, people carry with them their own emotional history and expectations, elements of which will shape these group-level expectations (Druskat \& Pescosolido, 2002) and can influence subsequent group behaviour (Peterson \& Behfar, 2003) regarding dealing with affective dynamics in the team.

Building on these arguments, we propose that based on their history of interactions, teams start with expectations of their potential GEA which will shape their work together. These interactions can be as a team but also between individual group members. As we are primarily interested in how early GEA can emerge and what the minimal requirements for it to do so are, we will focus on the latter premise: GEA emerging as an expectation based on previous experience between individual members' dyadic interactions. In line with Santos and Passos (2013) and Tasa et al (2007), we propose that early expectations which group members have about the level of emotional awareness dynamics in their team 
Running head: The development and function of group emotional awareness

will impact subsequent group dynamics in the same direction as actual group emotional awareness ability proper. As one of the most documented effects of GEA is decoupling task and relationship conflict (Ayoko et al., 2008; Boroș et al., 2016; Boroș, under review) we propose that expectations about a group's general level of emotional awareness (based on past dyadic interactions between its group members) in themselves should decouple the escalation of task into relationship conflict. Along these lines, we predict that:

Hypothesis 2: Expected group emotional awareness moderates the relation between task and relationship conflict in such a way that in groups with higher expectations of emotional awareness, the positive link between the two types of conflict is weaker than in groups with lower expectations.

\section{Method}

\section{Study 1}

In Study 1 we explore in an experimental setting the formation of group emotional awareness and regulation as emergent states, as a result of compositional effects (team members' self-perceptions of their individual emotional awareness capabilities) and group norms regarding emotional awareness.

Design

Emotional awareness norms manipulation. The following emotional awareness norms intervention is based on Druskat and Wolff's conceptualization of group emotional awareness (2001) and has two dimensions for the awareness norms: interpersonal understanding and perspective taking. These dimensions have been found to be at the core of developing norms for an emotionally aware atmosphere in the group. Hence, we used the operationalization of these dimensions proposed by Druskat and Wolff (2001: 87), the following instruction was given to respondents to read before they were handed in the instructions for the task they needed to work on:

\section{'Read carefully the following information before you start:}

Working in diverse groups requires heightened empathic abilities from group members. This ensures possibility of expression from all group members, and, more importantly, the recognition of these responses. Being able to decipher your own and other people's emotions is an important part of sensitivity awareness trainings.

Therefore, your performance will benefit if you implement the following strategies in your teamwork:

1. Have a "check in" at the beginning of the meeting - that is, ask how everyone is doing. 
Running head: The development and function of group emotional awareness

2. Assume that undesirable behaviour takes place for a reason. Find out what that reason is. Ask questions and listen. Avoid negative attributions.

3. As the work proceeds, tell your team-mates what you are thinking and how you are feeling about the process.

4. When you make decisions, ask whether everyone agrees with the decision.

5. Question the quickness of taking a decision.

6. Ask quiet members what they think.

The first three items of the instructions were reflecting interpersonal understanding, whereas the latter three, perspective taking. To respect Druskat and Wolff's (2001) model, we used the verbatim formulations provided by the authors and clustered under their respective sub-dimensions.

Manipulation check: group emotional awareness as an emergent state. At the end of the task, along with the other measures, students responded a brief scale assessing group emotional awareness (Boroș $\&$ al, 2016; Curșeu, Pluut et al., 2015). The three items for the manipulation check were: 'We knew how everyone felt just by looking at each other.'; 'We could tell how everyone felt by listening to the tone of our voices.', and 'Most of the time, we had a good sense of how each group member felt, even if they did not express it in words.' The Cronbach's alpha for this scale was .65.

\section{Measures}

Emotional awareness at individual level was measured with two of the subscales of the Trait MetaMood Scale - TMMS (Salovey et al., 1995): attention to feelings (i.e., how much attention individuals pay to their inner feelings and emotional states) - 13 items - and clarity of experience of feelings (i.e., the ability to understand and discriminate among feelings) - 13 items. Scores on the TMMS are held to assess stable, individual differences in the manner in which people respond to their feeling states (Fitness \& Curtis, 2005). The answers were recorded on a five-point Likert scale (from $1=$ strongly disagree to $5=$ strongly agree). Examples of items are 'The best way for me to handle my feelings is to experience them to the fullest.' (for attention to feelings) and 'I am rarely confused about what my feelings are.' (for clarity of experience of feelings). The Cronbach's alpha for this scale was .78.

Group emotion regulation. The five items evaluating group emotion regulation were measured with the scale proposed by Curşeu et al. (2012) (e.g., "The group was generally able to influence how individual members felt"). Answers were recorded on a Likert scale ranging from 1 (= not at all) to 5 (= very much). Scores on items such as "It was difficult to calm down quickly when we got mad at each other" were reversed so that higher scores reflected more effective emotion regulation. The Cronbach's alpha was .72 . 
Running head: The development and function of group emotional awareness

For all the above variables, individual scores were aggregated at group level by computing the mean score for a group of respondents. Given the presence of a manipulation, we centred the independent variable for the interaction effect tests.

\section{Respondents and procedure}

168 students (aged 17-26, with a mean age of $19.98, \mathrm{SD}=1.64$ ) from a $1^{\text {st }}$ year Bachelor degree at a Dutch university were organized in 33 groups composed of 3-6 members and participated in a classroom activity. The 15 experimental groups underwent the emotional awareness manipulation, and 18 groups served as control (i.e., no emotional awareness manipulation).

Students participated in a one-hour creativity exercise. Their task was to build a freestanding tower from newspapers that reached the ceiling of the room. They were grouped in teams of 3-6 members, and were handed in the instructions and the materials (i.e., newspapers). The experimental groups received on the instruction sheet the instructions for creating emotional awareness norms in addition to the ones about how to build the tower, whereas the control groups only received the instructions on how to build the tower. Experimental and control groups did not work in the same room, in order to avoid the spill-over effect. At the end of one hour, students filled in the manipulation check and emotion regulation questionnaire.

Results

The descriptive statistics for the variables in the model and the matrix of intercorrelations are presented in Table 1.

Insert Table 1 about here

Manipulation check. For Study 1, groups in the emotional awareness norms condition (means= 3.39 $\mathrm{SD}=.32$ ) did not present significantly higher levels of group emotional awareness ( $\mathrm{t}$-test $=0.92$, sig $=.76$ ) than control groups (i.e., without the awareness manipulation: means $=3.35, \mathrm{SD}=.39$ ).

Given our hypothesis about the interaction effect of individual awareness and group awareness norms, we explored whether the apparent lack of effect of our manipulation might in fact also reflects this moderation relation. We hence proposed that the manipulation had an effect for groups whose members had an overall lower emotional awareness as compared to groups with high individual emotional awareness. Based on previous research, we can expect groups with emotionally aware members to implicitly develop these norms for group emotional awareness without any need for instructions to do 
Running head: The development and function of group emotional awareness

so. Therefore, our manipulation would not add significantly to their awareness. As one can observe in Figure 1, these expectations were met: while group emotional awareness presents an ascendant slope for groups with low individual awareness, the slope for high individual awareness is almost horizontal with a negative tendency.

Insert Figure 1 about here

In order to test our moderation hypothesis (H1), we conducted a regression analysis to estimate the impact of the two-way interaction of individual emotional awareness and group emotional awareness manipulation on group emotion regulation. We controlled for group size at step 1, then entered individual emotional awareness and group emotional awareness manipulation in the second step and the cross-product term in the third. As hypothesized, groups that build emotional awareness norms compensate for their members' low awareness and develop just as good strategies as groups formed of emotionally aware people (see Table 2). However, personal propensity towards awareness doubled by explicit awareness norms blocks the development of regulatory strategies (see Figure 2). The gradient of the interaction slope was $-1.50,(\mathrm{t}$ slope $=-3.072$ at a significance level of 0.005$)$.

Insert Table 2 and Figure 2 about here

\section{Study 2}

Building on the results of Study 1, in Study 2 we set out to explore further two other characteristics of emergence: coherence and ostensiveness. We proposed that as an emergent state, GEA can emerge first as expectations (based on past history - which does not need to be shared by the group as a whole but builds on dyadic experiences with other members). These expectations of group emotional awareness will in turn impact the group members' behaviours and act along the line of GEA itself. To examine this, we tested the impact of group emotional awareness expectations on the interplay between task and relationship conflict in teams where team members had previous work experience with each other.

\section{Respondents and procedure}

Participants were 220 students ( $83 \%$ women, with an average age of 20.67) at a Romanian university, $1^{\text {st }}$ year of Bachelor, $1^{\text {st }}$ semester, who were part of the same seminar group. As they would attend all 
Running head: The development and function of group emotional awareness

seminars together, the students knew each other and had worked with each other in the past (but not necessarily as a whole group and not to the same extent - i.e., with some more than others) or at least seen each other interact during seminars (workshops). Students were organized in 48 groups of 4-6 members (self-selected), who were asked to participate in a 15-minute creative group exercise. The task consisted of finding a way to release an egg into a bowl, in such a way that the egg would not break. Each group received several objects they could use during the task: six drinking straws of equal sizes, a 1-m long plastic stripe, duct tape and a plastic bowl. The task was collaborative in nature, as well as a fun, engaging challenge. The time pressure was aimed at prompting an acceleration of group dynamics.

Before the task, participants were asked individually to fill out a questionnaire of expectations for emotional awareness of their team, as well as other measures (such as the extent to which they knew each member of their team). After finishing the task, the participants were asked to fill out a questionnaire of teamwork perceptions regarding conflicts developed in the group, as well as emergent group emotional awareness.

\section{Measures}

We measured group emotional awareness expectations by six items adapted from Eby, Meade et al.'s questionnaire for teamwork quality (1999). To ensure that we measure the same things across the two studies, the selected items were fully aligned with Druskat and Wolff's (2001) definition and operationalization of norms for group emotional awareness and the derived experimental manipulation we used in Study 1. Sample items included: 'The team will ask quieter people to speak up.'; 'The team will offer emotional support to its members.'; 'The personalities of all team members will be respected in this team'. The answers were recorded on a five-point Likert scale (from 1 - strongly disagree to 5 strongly agree). The alpha Cronbach for the scale was .71.

At the end of the task we measured task and relationship conflict by eight items (four for task conflict and four for relationship conflict) from the intra-team conflict scale introduced by Jehn (Jehn, 1997; Jehn, Northcraft \& Neale, 1999). The answers were recorded on a five-point Likert scale (from 1 strongly disagree to 5 - strongly agree). Cronbach's alpha for task conflict was 0.74 and for relationship conflict 0.66 . The low alpha for relational conflict, while posing a clear limitation for this study and the generalizability of its findings, is also important to acknowledge per se, in light of our frame about the coherent characteristic of emergent states: some states do take longer to emerge. We acknowledge that 15 minutes is indeed a very brief period of time to develop intense relational conflicts (confirmed by the low level of relational conflicts shown in the data - i.e., an average of 1.77) even to the extent of being able to give consistent answers about this type of conflicts. 
Running head: The development and function of group emotional awareness

We also controlled for the degree of familiarity before the task. To assess this, participants had to answer on a scale from 1 to 10 how well they knew each member upfront. The scores varied between 1 (7.7\% of responses) and 10 (3.2\% of responses), with a mean of 5.37 and a median of 5.58 . We averaged the individual scores for all team members, and then computed the group mean score and standard deviation.

The second variable we controlled for was emergent group emotional awareness (measured after the task). We measured it with the same items as group emotional awareness expectations, except formulated in the past tense and measured at the end of the task. The Cronbach alpha for the scale was .70 .

\section{Results}

The descriptive statistics for the variables in the model and the matrix of intercorrelations are presented in Table 3. We aggregated the individual level data at group level by computing the group means. We then centred our variables before conducting our regression analyses at group level.

Insert Table 3 about here

To test Hypothesis 2, we conducted a regression analysis to estimate the impact of the two-way interaction of task conflict and group emotional awareness expectations on relationship conflict. Familiarity with group members and emergent group emotional awareness were controlled for in step 1. Group emotional awareness expectations and levels of task conflict were entered in the second step and the cross-product term in the third step.

Results show that high group emotional awareness expectations (based on previous knowledge of the team members and measured before the task) indeed decrease the chance that task conflict will evolve into relationship conflict (see Table 4), even while controlling for emergent group emotional awareness (measured at the end of the task). The impact of group emotional awareness expectations is as follows: when there are expectations of high group emotional awareness, these expectations will reduce the likelihood of task conflict evolving into relationship conflict. When expectations are of low group emotional awareness, the two types of conflict are much more closely related. This effect is present even in the span of 15 minutes.

As expected, group emotional awareness has a marginally significant (negative) impact on the development of relational conflict. However, it is interesting that the interaction effect of expectations of group emotional awareness and task conflict remains significant even while controlling for the actual 
Running head: The development and function of group emotional awareness

(emergent) group emotional awareness. What the data tells us is that expectations of an emergent state already shape group dynamics, bringing strong evidence to support ostensiveness (i.e., the experience of a state influences behaviour, which in turn influences the further shaping of that state).

Insert Table 4 and Figure 3 about here

\section{General discussions}

We set out to gain a better understanding of the conceptualization and measurement of group emotional awareness. To do this, we adopted a new approach for conceptualizing group emotional awareness. So far, previous studies have only measured this concept either as an aggregation of individual emotional awareness of group members (Kelly \& Barsade, 2001; Jordan \& Troth, 2002), or as group norms supporting awareness (Druskat \& Wolff, 2001). By considering group emotional awareness as an emergent state, we proposed that it is a function of both members' characteristics and group norms, as well as showed that it is shaped by pre-existing expectations. Our designs to explore emergence through its four main characteristics (global, radically novel, coherent and ostensive) added new insights into the emergence and functioning of group emotional awareness.

Study 1 showed that groups composed of individuals who rate themselves high on emotional awareness seem to develop on their own group norms for emotional awareness in their interactions (their measured group emotional awareness differs only marginally from groups who received such norms, irrespective of their members' individual emotional awareness levels). What is more interesting though is that group emotion regulation emerged either in groups with higher levels of individual emotional awareness without given norms or lower levels of individual emotional awareness which received group awareness norms, but not in groups with both high individual emotional awareness and received norms. It seems that indeed these groups were stuck on emotional awareness stimuli and unable to shift their focus to develop the needed emotion regulation strategies. These findings are in line with previous research on attentional deployment and emotion regulation (Wadlinger \& Isaacowitz, 2011). Because attentional resources are limited, salient stimuli that capture the attention further direct our choices and behaviours. Several factors contribute to the salience of certain stimuli, and motivation is a primary factor. Therefore, if people define themselves as being emotionally aware and are given a set of norms that focuses their attention on group emotional awareness, their attention will be primarily directed at processing emotional stimuli and trying to understand them better. This means an increase in attention concentration but reduced attentional flexibility. However, greater attentional flexibility has been proven to promote emotion regulation through easier disengagement from irrelevant negative information and more frequent shifts of attention towards positive information. This possible 
Running head: The development and function of group emotional awareness

mechanism might explain also why in Elfenbein et al.'s (2007) study, accurate appraisal of positive emotions promoted better teamwork, whereas accurate appraisal of negative emotions was detrimental: teams got stuck on processing negative emotion stimuli and were unable to shift their attention from them and focus on the task, expand their 'internal conceptual space' (Wadlinger \& Isaacowitz, 2011) or search for sources of positive information. Further research is needed to explore the link between group emotional awareness, attentional deployment and group emotion regulation, as well as the possible differences in how group emotional awareness and regulation operate for positive and negative emotions. For now, our data points to the importance of team members' cognitive representation about their own and the other's emotional capabilities for determining subsequent behaviour. Study 1 brings evidence that these representations might trigger the attention focus of the team on emotional stimuli to such an extent as to hinder the development of emotion regulation strategies.

Study 2 however looks at the positive side of this reality and brings evidence that the simple expectations about group emotional awareness in a team that has worked together before (therefore experience-induced expectations) is sufficient to decouple the co-occurrence of task and relationship conflict. These findings support theoretical speculations (Kelly \& Barsade, 2001) that expectations formed through the group's emotional history may serve to impose a self-fulfilling affective tone or emotion on the group. Furthermore, we offer evidence that emergent states, such as GEA, are shaped by team member's expectations before the actual work together. This adds to self-efficacy literature (Tasa et al., 2007) and broadens the range of possible group phenomena that might fall under this category (i.e., self-fulfilling prophecies). Should this line of research bring further evidence in line with our findings, the implications for practice are extensive. It would mean that more attention needs to be paid at the set-up stage of groupwork and into shaping the expectations about working together. Further explorations along these lines are therefore much needed.

A final theoretical contribution was that in exploring coherence through linking the emergence of group emotional awareness to group emotion regulation, we moved away from multi-faceted models of emotional capabilities (e.g., Druskat \& Wolff, 2001; Salovey \& Mayer, 1990) and aligned with recent research that conceptualizes them in terms of temporal succession (i.e., the cascading model of Joseph and Newman, 2010). The implications for both how we study and work with emotional capabilities is a shift in traditional framings, a shift that could bring further clarity in the conceptual fuzziness around emotional capabilities in organisations (Daus et al., 2012).

Finally, our conceptualization of GEA as an emergent state has clear methodological implications, most notably in giving arguments for what it is that different ways to measures group emotional awareness will actually reflect. We showed that both group norms and group-level aggregations of individual measures of emotional awareness are only elements that build the emergence of group emotional awareness, and the latter cannot be properly measured through either of them alone (due to the radical novelty of an emergent state). Consequently, we support reference-shift consensus models of 
Running head: The development and function of group emotional awareness

emergence, whereby "researchers capture the experience of the group as a whole by asking members to report on or evaluate a group-level construct or experience in their team" (Waller et al., 2016: 580). Both Study 1 and 2 provide new evidence about the predictive power of group representations of affective capabilities. In doing so, we also add to the evidence supporting mixed-method measurements of emotional capabilities (Joseph et al., 2015).

\section{Limitations and future research directions}

In Study 1, we opted to measure individual emotional awareness as a self-report instead of ability. While we offered theoretical justification for our choice, we think it is relevant that future research would instead investigate these propositions with ability measures. Complementing the findings from selfreport with ability measures would help shed further light onto the complex dynamics represented by the development of group emotional awareness and regulation as emergent states.

In Study 2 we worked with expected group emotional awareness, basing ourselves on previous reciprocal knowledge of the group members. It is important to note however that we did not measure in this study either the past history of the groups (if in the full composition of the team in the experiment they had worked together before, and if so, how many times), or conflict history. We started from a generic stance of trying to understand how quickly group emotional awareness can emerge to a strong enough degree to impact subsequent group dynamics. The focus of this study was on the emergence characteristic of coherence, and on revealing the minimal conditions needed for this particular emergent state (i.e., group emotional awareness) to come to be and impact subsequent dynamics (i.e., the escalation of task into relationship conflict). We acknowledge that a crucial next step is to control for these variables, as they speak directly to the emergence phenomenon.

\section{Implications for practice}

Our findings also other have practical implications for approaching teamwork. There is an on-going debate on the uses and abuses of emotional intelligence measures in personnel selection, and the added value of this construct in predicting job performance. Our study points to the benefits of measuring individual members' emotional intelligence (more precisely, emotional awareness) for a different purpose. Paraphrasing Freddy Mercury's ‘too much love will kill you', we draw attention to the negative impact of having interventions aimed at enhancing group emotional awareness norms in groups with highly emotionally aware people for the development of subsequent group emotion regulation. Therefore, knowing in advance how the members of a group score on emotional awareness helps to decide if a group benefits or not from interventions aimed at improving cooperation by enhancing group emotional awareness norms. Our findings also offer a hopeful view that even if people do not have advanced emotional awareness capabilities, this can be compensated through group-level interventions. Previous research showed that developing such norms also helps with managing diversity in teams, in 
Running head: The development and function of group emotional awareness

that teams that did not have diversity beliefs could still reap the benefits of diversity in their teams if they developed emotional awareness norms (Boroș \& Curșeu, 2013).

It is important to remember that group emotional awareness interventions (in the form of discussing group norms to guide them) are most needed precisely where they are desired the least - in groups that think emotional awareness is part of the 'soft skills' that distract from efficiency. Previous research has already demonstrated that groups that have group emotional awareness do in fact perform better in conflict situations, by decoupling task and relationship conflict (Boroș, under review) and by improving coordination processes through alignment when faced with conflict asymmetry (Boroș et al., 2016).

Lastly, our second study shows that not only does group emotional awareness emerge early in the groupwork, but it is already shaped by expectations that group members bring with them. In terms of interventions, these findings suggest that any group project will benefit from early interventions. Group dynamics research has argued since Tuckman (1965) that the start of teamwork is dedicated to teamwork rather than taskwork. This means that interventions on teamwork are more impactful in the first half of a group project's life. We now have additional evidence to advocate for interventions that help to shape the early perceptions of team members of each other and their projections concerning how their collaboration will be. Interventions aimed at focusing on positive expectations about working together at the start of a project appear to offer a meaningful, long-term advantage for group dynamics and the effectiveness of work teams.

\section{References}

Ackerman, P.L. and Kanfer, R., 2009. Test length and cognitive fatigue: an empirical examination of effects on performance and test-taker reactions. Journal of Experimental Psychology: Applied, 15(2), p.163-181.

Ayoko, O.B., Callan, V.J. and Härtel, C.E., 2008. The influence of team emotional intelligence climate on conflict and team members' reactions to conflict. Small Group Research, 39(2), pp.121-149.

Barsade, S.G. and Gibson, D.E., 2012. Group affect: Its influence on individual and group outcomes. Current Directions in Psychological Science, 21(2), pp.119-123.

Barsade, S.G., 2002. The ripple effect: Emotional contagion and its influence on group behavior. Administrative Science Quarterly, 47(4), pp.644-675.

Baumeister, R.F., Bratslavsky, E., Muraven, M. and Tice, D.M., 1998. Ego depletion: Is the active self a limited resource?. Journal of Personality and Social Psychology, 74(5), pp.1252-1265.

Black, J., Kim, K., Rhee, S., Wang, K., \& Sakchutchawan, S. (2019). Self-efficacy and emotional intelligence, Team Performance Management, 25 (1/2), pp. 100-119. 
Running head: The development and function of group emotional awareness

Boroș S. \& Curșeu, P.L. (2013).'Would you like to talk about that?' How and when group emotional awareness enhances effectiveness of gender diverse teams. Psihologia Resurselor Umane, 11(2), pp. 4546.

Boroş, S., Van Gorp, L., Cardoen, B., \& Boute, R. (2017). Breaking Silos: A Field Experiment on Relational Conflict Management in Cross-Functional Teams. Group Decision and Negotiation, pp. 327-356.

Cronin, M. A., Weingart, L. R., \& Todorova, G. (2011). Dynamics in groups: Are we there yet? The Academy of Management Annals, 5(1), 571-612.

Curșeu, P., Boroș, S., \& Oerlemans, L. (2012). Task and relationship conflict in ad-hoc and permanent groups: The critical role of emotion regulation. International Journal of Conflict Management, 23(1), pp. 97-10.

Curșeu, P.L., Pluut, H., Boros, S., \& Meslec, M.N. (2015). The magic of collective emotional intelligence in learning groups: No guys needed for the spell!. British Journal of Psychology, 106 (2), pp. 217-234.

Daus, C. S., Dasborough, M. T., Jordan, P. J., \& Ashkanasy, N. M. (2012). Chapter 14. We are all Mad in Wonderland: An Organizational Culture Framework for Emotions and Emotional Intelligence Research. In Experiencing and managing emotions in the workplace (pp. 375-399). Emerald Group Publishing Limited.

Druskat, V. U., \& Pescosolido, A. T. (2002). The content of effective teamwork mental models in selfmanaging teams: Ownership, learning and heedful interrelating. Human Relations, 55(3), pp. 283-314. Druskat, V. U., \& Wolff, S. B. (2001). Building the emotional intelligence of groups. Harvard Business Review, 79, pp. 81-90.

Eby, L. T., Meade, A. W., Parisi, A. G., \& Douthitt, S. S. (1999). The development of an individuallevel teamwork expectations measure and the application of a within-group agreement statistic to assess shared expectations for teamwork. Organizational Research Methods, 2(4), pp. 366-394.

Elfenbein, H. A., Foo, M. D., White, J. B., Tan, H. H., \& Aik, V. C. (2007). Reading your counterpart: The benefit of emotion recognition accuracy for effectiveness in negotiation. Journal of Nonverbal Behavior, 31, pp. 205-223.

Elfenbein HA (2006) Team Emotional Intelligence: What it can mean and how it can impact performance. In: Druskat V, Sala F, Mount G (Eds.) The link between emotional intelligence and effective performance, Lawrence Erlbaum, Mahwah, pp. 165-184.

Elfenbein, H.A. \& Ambady, N. (2002). Predicting workplace outcomes from the ability to eavesdrop on feelings. Journal of Applied Psychology, 87, pp. 963-971.

Fitness, J., \& Curtis, M. (2005). Emotional intelligence and the Trait Meta-Mood Scale: Relationships with empathy, attributional complexity, self-control, and responses to interpersonal conflict. E-Journal of Applied Psychology, 1, pp. 50-62. 
Running head: The development and function of group emotional awareness

Gross, J. J., \& Thompson, R. A. (2007). Emotion regulation: Conceptual foundations. In J. J. Gross (Ed.), Handbook of emotion regulation, Guilford Press, New York, NY, pp.3-24

Hatfield ,E., Cacioppo, J., \& Rapson, R.L. (1994). Emotional Contagion, Cambridge University Press, New York.

Humphrey, S. E., \& Aime, F. (2014). Team microdynamics: Toward an organizing approach to teamwork. The Academy of Management Annals, 8(1), 443-503.

Ilgen, D. R., Hollenbeck, J. R., Johnson, M., \& Jundt, D. (2005). Teams in organizations: From inputprocess-output models to IMOI models. Annual Revue of Psychology, 56, pp. 517-543.

Jehn, K. A. (1997). A qualitative analysis of conflict types and dimensions in organizational groups. Administrative science quarterly, pp. 530-557.

Jehn, K. A., Northcraft, G. B., \& Neale, M. A. (1999). Why differences make a difference: A field study of diversity, conflict and performance in workgroups. Administrative science quarterly, 44(4), pp. 741763.

Jordan P, J., \& Troth, A. C. (2002). Emotional intelligence and conflict resolution: Implications for human resource development. Advances in Developing Human Resources, 4, pp. 62-79.

Jordan, P. J., \& Troth, A. C. (2004). Managing emotions during team problem solving: Emotional intelligence and conflict resolution. Human Performance, 17, pp. 195-218.

Joseph, D. L., Jin, J., Newman, D. A., \& O'Boyle, E. H. (2015). Why does self-reported emotional intelligence predict job performance? A meta-analytic investigation of mixed EI. Journal of Applied Psychology, 100(2), pp. 298-342.

Joseph, D.L. \& Newman, D.A. (2010). Emotional Intelligence: An Integrative Meta-Analysis and Cascading Model. Journal of Applied Psychology, 95, pp. 54-78.

Kelly, J., \& Barsade, S. (2001). Mood and emotions in small groups and work teams. Organizational Behavior and Human Decision Processes, 86 (1), pp. 99-130.

King, K. G. (2017). The impact of within-team variance on transactive memory system development and team performance. Team Performance Management: An International Journal, 23(3), pp. 124-135. Lazarus, R. S. (1991). Emotion and adaptation, Oxford University Press, New York, NY.

Marks, M. A., Mathieu, J. E., \& Zaccaro, S. J. (2001). A temporally based framework and taxonomy of team processes. Academy of Management Review, 26(3), pp. 356-376.

Mayer, J.D., Roberts, R.D., \& Barsade, S.G. (2008). Human Abilities: Emotional Intelligence. Annual Review of Psychology, 59, pp. 507-36.

Michinov, E., \& Juhel, J. (2018). Multilevel influences of team identification and transactive memory on team effectiveness. Team Performance Management: An International Journal, 24(1/2), pp. 106120.

Quoidbach, J., \& Hansenne, M. (2009). The impact of trait emotional intelligence on nursing team performance and cohesiveness. Journal of Professional Nursing, 25(1), pp. 23-29. 
Running head: The development and function of group emotional awareness

Peterson, R. S., \& Behfar, K. J. (2003). The dynamic relationship between performance feedback, trust, and conflict in groups: A longitudinal study. Organizational Behavior and Human Decision Processes, 92(1-2), pp. 102-112.

Santos, C. M., \& Passos, A. M. (2013). Team mental models, relationship conflict and effectiveness over time. Team Performance Management: An International Journal, 19(7/8), 363-385.

Salovey, P. \& Mayer, J.D. (1990). Emotional intelligence. Imagination, Cognition, and Personality, 9 , pp. 185-211.

Salovey, P., Mayer, J.D., Goldman, S.L., Turvey, C. and Palfai, T.P., 1995. Emotional attention, clarity, and repair: Exploring emotional intelligence using the Trait Meta-Mood Scale. In: Pennebaker JW (Ed) Emotion, disclosure, and health, American Psychological Association, Washington, D.C. pp. 125-154. Sung, S. Y., \& Choi, J. N. (2012). Effects of team knowledge management on the creativity and financial performance of organizational teams. Organizational Behavior and Human Decision Processes, 118(1), pp. 4-13.

Tasa, K., Taggar, S., \& Seijts, G. H. (2007). The development of collective efficacy in teams: A multilevel and longitudinal perspective. Journal of Applied Psychology, 92, 17-27.

Tuckman, B. W. (1965). Developmental sequence in small groups. Psychological Bulletin, 63(6), 384399.

Vohs, K. D., Baumeister, R. F., Schmeichel, B. J., Twenge, J. M., Nelson, N., M., \& Tice, D. M. (2008). Making choices impairs subsequent self-control: A limited-resource account of decision making, selfregulation, and active initiative. Journal of Personality and Social Psychology, 94, pp. 883-898.

Wadlinger, H. A., \& Isaacowitz, D. M. (2011). Fixing our focus: Training attention to regulate emotion. Personality and Social Psychology Review, 15(1), pp. 75-102.

Wegner, D. M. (1987). Transactive memory: A contemporary analysis of the group mind. In Theories of group behaviour, Springer, New York, NY, pp. 185-208.

Yang, J. \& Mossholder, K. W. (2004). Decoupling task conflict and relationship conflict: The role of intragroup emotional processing. Journal of Organizational Behavior, 25, pp. 589-605. 
Running head: The development and function of group emotional awareness

\section{TABLES AND FIGURES}

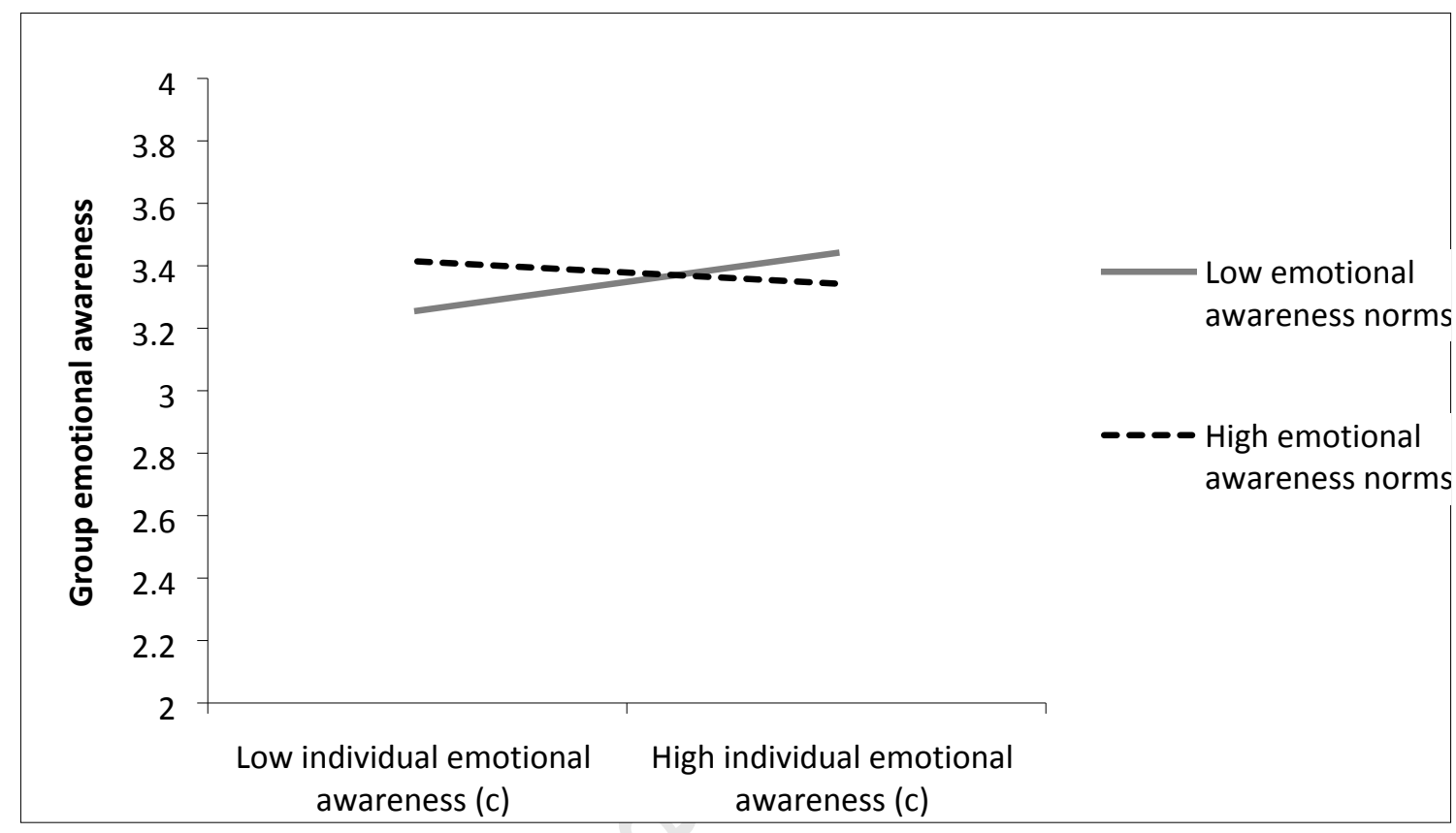

Figure 1. Study 1. Interaction slopes for individual awareness and group awareness manipulation on the emergence of group emotional awareness 
Running head: The development and function of group emotional awareness

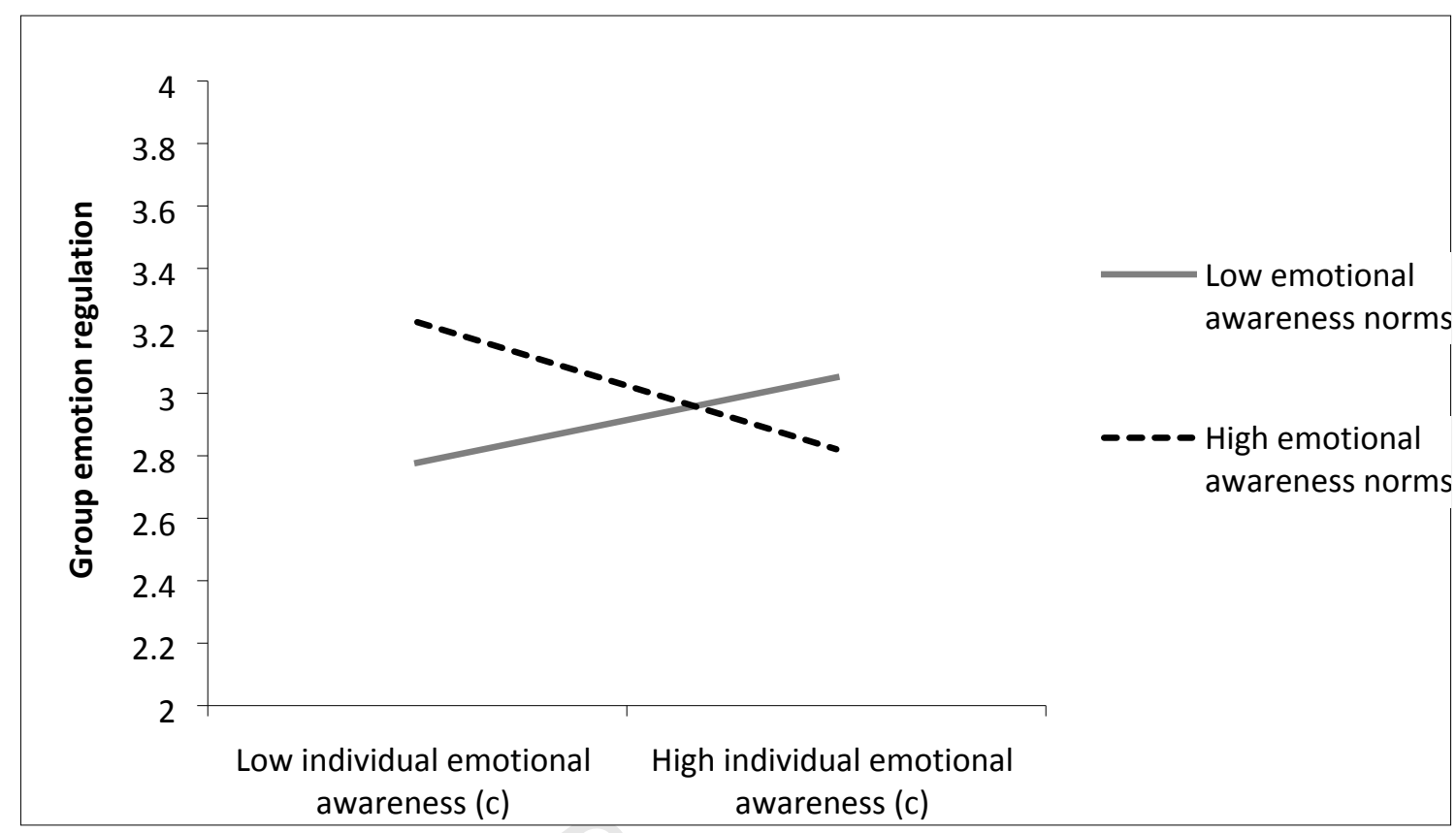

Figure 2. Study 1. Interaction slopes for individual awareness and group awareness manipulation on the emergence of group emotion regulation 
Running head: The development and function of group emotional awareness

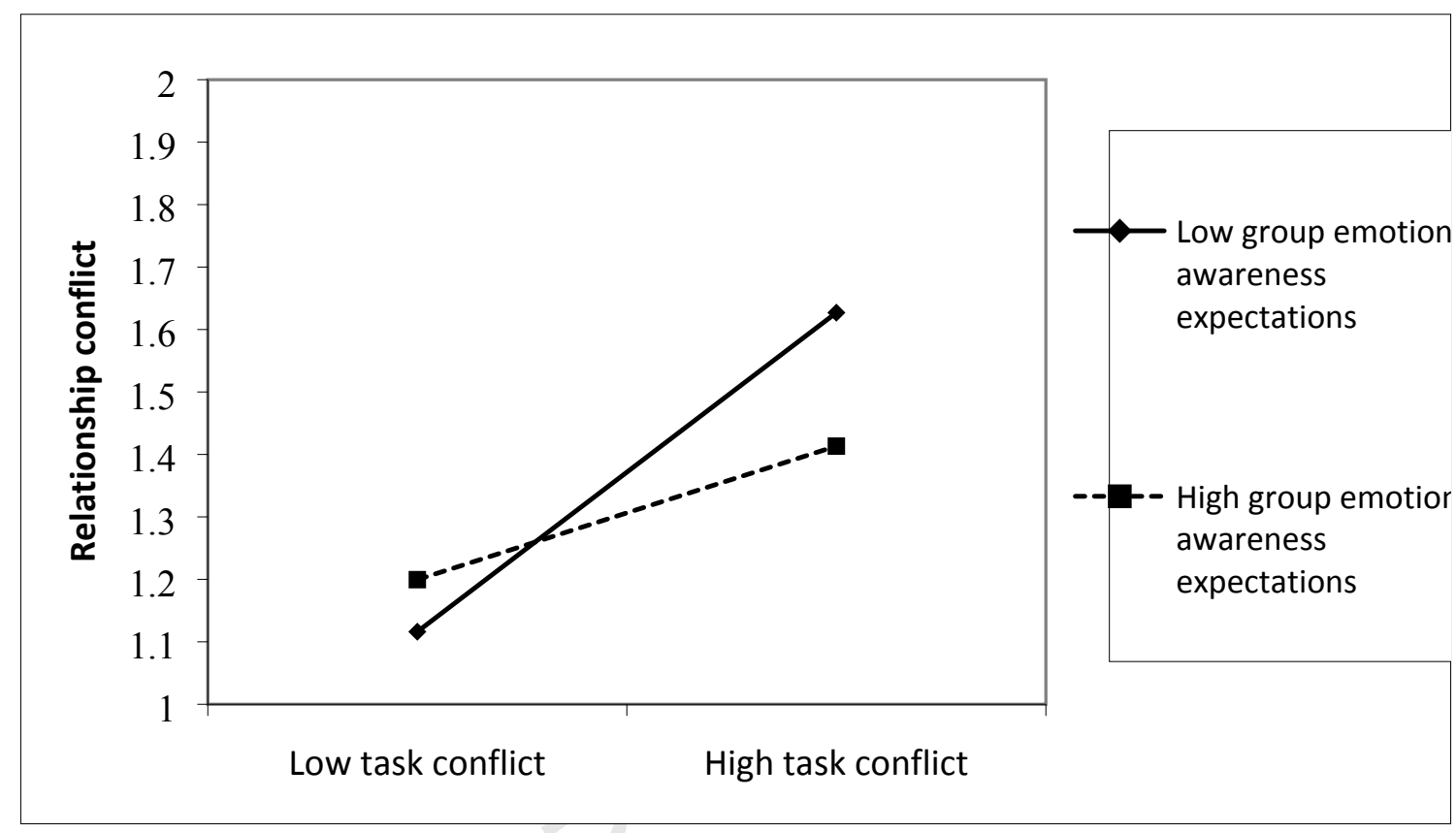

Figure 3. Study 2. Interaction slopes task conflict and group emotional awareness expectations on relationship conflict 
Table 1. Correlation matrix and descriptive statistics for Study 1 (the impact of individual emotional awareness and group emotional awareness manipulation on group emotion regulation)

\begin{tabular}{|c|c|c|c|c|c|c|c|}
\hline & Mean & S.D. & $\begin{array}{l}\text { Percentage } \\
\text { women }\end{array}$ & Group size & $\begin{array}{c}\text { Group } \\
\text { emotional } \\
\text { awareness } \\
\text { norms }\end{array}$ & $\begin{array}{l}\text { Individual } \\
\text { emotional } \\
\text { awareness }\end{array}$ & $\begin{array}{c}\text { Group } \\
\text { emotion } \\
\text { regulation }\end{array}$ \\
\hline Percentage women & .45 & .28 & 1 & -.29 & -.07 & .30 & -.16 \\
\hline Group size & 5.00 & .95 & & 1 & .14 & .12 & $-.44^{* *}$ \\
\hline $\begin{array}{l}\text { Group emotional } \\
\text { awareness norms } \\
\text { (manipulation) }\end{array}$ & .45 & .50 & & & 1 & .02 & .18 \\
\hline $\begin{array}{l}\text { Individual emotional } \\
\text { awareness }\end{array}$ & 3.75 & .21 & & & & 1 & .02 \\
\hline $\begin{array}{l}\text { Group emotion } \\
\text { regulation }\end{array}$ & 2.97 & .31 & & & & & 1 \\
\hline
\end{tabular}


Table 2. Regression results for the two-way interaction between group emotional awareness manipulation and individual emotional awareness (centred) on group emotion regulation (Study 1)

\begin{tabular}{|c|c|c|c|c|}
\hline & \multirow[t]{2}{*}{ Model/Step } & \multicolumn{3}{|c|}{$\frac{\text { Group emotion }}{\text { regulation }}$} \\
\hline & & 1 & 2 & 3 \\
\hline 1. & Group size & $-.44 *$ & $-.48 * *$ & -.33 \\
\hline 2. & Group emotional awareness norms (manipulation) & & .23 & $7.83^{*}$ \\
\hline & Individual emotional awareness & & .08 & .33 \\
\hline 3. & $\begin{array}{l}\text { Interaction awareness manipulation*individual emotional } \\
\text { awareness }\end{array}$ & & & $-7.65 *$ \\
\hline $\begin{array}{l}\text { F } \\
\text { change }\end{array}$ & & $7.21 *$ & 1.12 & $5.80^{*}$ \\
\hline $\mathrm{R}^{2}$ & & .19 & .25 & .39 \\
\hline $\operatorname{Adj} R^{2}$ & & .17 & .17 & .30 \\
\hline
\end{tabular}


Table 3. Correlation matrix and descriptive statistics for Study 2 (the impact of group emotional awareness expectations on the relation between task and relationship conflict) - uncentered variables

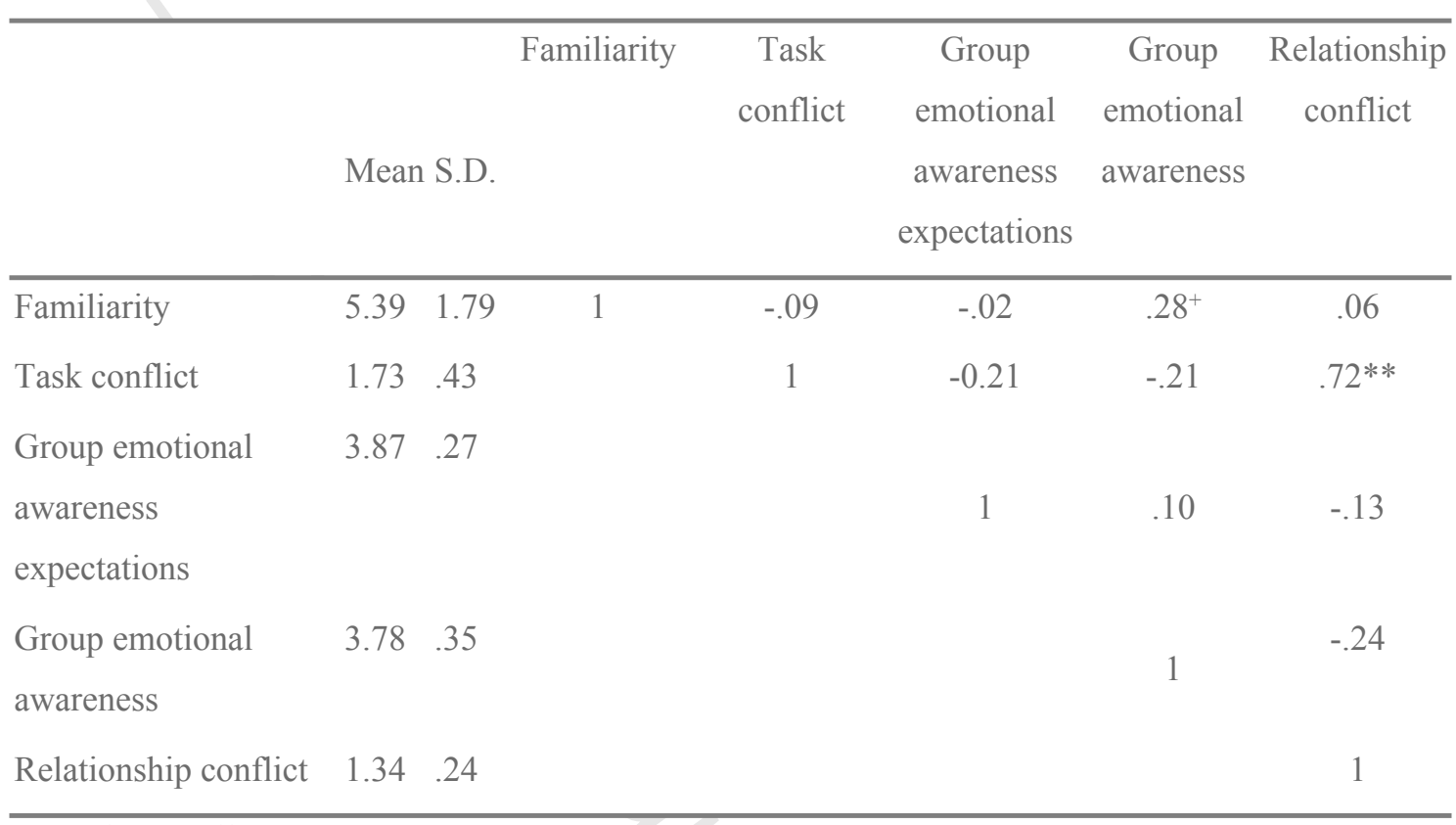

${ }^{+} \mathrm{p}<.1 ;{ }^{*} \mathrm{p}<.05 ;{ }^{* *} \mathrm{p}<.01$ 
Table 4. Study 2: Regression results for the two way interaction between group emotional awareness expectations and task conflict on relationship conflict (centred variables)

\begin{tabular}{|c|c|c|c|}
\hline \multirow[t]{2}{*}{ Model/Step } & \multicolumn{3}{|c|}{$\underline{\text { Relationship conflict }}$} \\
\hline & 1 & 2 & 3 \\
\hline 1. Familiarity & .20 & $.22 *$ & $.29 * *$ \\
\hline Group emotional awareness & $-.30^{+}$ & -.15 & $-.19^{+}$ \\
\hline Task conflict & & $.71 * * *$ & $.74 * * *$ \\
\hline Group emotional awareness expectations & & -.09 & -.14 \\
\hline 3. Interaction Task conflict*awareness expectations & & & $-.30 * *$ \\
\hline F change & 2.222 & $24.72 * *=$ & $9.49 * *$ \\
\hline $\mathrm{R}^{2}$ & .09 & .58 & .66 \\
\hline $\operatorname{Adj}^{2}$ & .05 & .54 & .61 \\
\hline
\end{tabular}

